\title{
POTENSI PARIWISATA KERATON KASUNANAN SURAKARTA DI TINJAU DARI DAYA TARIK, LOKASI DAN PROMOSI
}

\author{
Septian Haryoko ${ }^{1)}$, Ida Aryati ${ }^{2)}$, Ratna Damayanti ${ }^{3)}$ \\ Fakultas Ekonomi Manajemen Universitas Islam Batik Surakarta ${ }^{1) 23)}$ \\ E-mail : tianseptian043@gmail.com ${ }^{1)}$
}

\begin{abstract}
The purpose of this study aims to determine the effect of Attraction Data, Location and Promotion of the Tourism Potential of the Surakarta Sultanate Palace. This type of Presearch is a quantitative description. ThePpopulation inPthis studyIwere visitors to the Surakarta Kasunanan Palace, amounting to 1223 using Purposive Sampling with 100 respondents. This study uses data analysis techniques in the form of multiple linear regression tests. The results of this study indicate that: (1) There is an influence of Attractiveness on Tourism Potential of Surakarta Palace of Kasunanan which is indicated by the regression coefficient value of 4.061 and the significance value is smaller than the level of significant (0,000 <0.050), (2) There is no influence of Location on Surakarta Potential Palace Keraton Tourism Potential shown by a regression coefficient of 0.369 and a significance value greater than the level of significant $(0.713>0.050)$, and (3) There is an influence on the Promotion of the Potential Surakarta Palace Keraton Tourism indicated by a regression coefficient of 3.249 and Significance value is smaller than the level of significant (0.002 $<0.050)$. There is a simultaneous influence of Attraction, Location and Promotion of Potential Tourism in Surakarta Sunanate Palace whichPis indicated by the coefficient of determination (R2) of 0.406 or $40.6 \%$ which means that Tourism Potentials of Surakarta Palace Kasunanan. The level of interest explained by the variables Attractiveness, Location and Promotion is $40.6 \%$ while the remaining $59.4 \%$ is explained by other factors.
\end{abstract}

Keywords: Attractiveness, Location, Promotion and Tourism Potential

\section{PENDAhUluan}

Indonesia memiliki potensi pariwisata yang sangat besar dan sumber daya yang belum sempat dikembangkan secara maksimal oleh sektor swasta ataupun pemerintah. Diharapkan dapat memberi manfaat bagi masyarakat setelah diadakan pembangunan di bidang pariwisata, karena pembangunan ekonomi salah satunya di bidang pariwisata. Kegiatan pariwisata diharapkan memberikan kontribusi yang cukup besar terhadap perekonomian. Wisata budaya merupakan jenis pariwisata minat khusus dengan memanfaatkan potensi sejarah. Untuk menjadi kawasan tujuan wisata budaya, ada unsur sejarah yang membedakan kota Surakarta dengan kota lain. Hal itu perlu di perhatikan dari daya tarik, lokasi dan promosi agar pengunjung tidak akan pindah kelain tempat apabila merasa senanag dan puas.

Di tengah aktivitas dan kesibukan masyarakat sehari-hari, berwisata sebuah hal yang sangat diperlukan oleh setiap orang. Wisatawan dapat memilih berbagai objek, dari wisata yang berbau alam, wisata yang berbau budaya bahkan wisata yang buatan manusia. Salah satu Negara yang mempunyai berbagai macam objek wisata adalah Indonesia di karenakan kebinekaannya. Oleh karena itu, Indonesia banyak di kunjungi oleh wisatawan manca Negara. 
Potensi wisata menurut Mariotti dalam Yoeti (1983: 160 - 162) mengemukakan pendapat bahwa sesuatu yang terdapat pada daerah tujuan wisata adalah daya tarik agar wisatawan mau berkunjung dan dapat mengembangkan perekonomian warga sekitar agar menjadi lebih baik.

Daya tarik dan objek wisata saling berhubungan untuk menarik wisatawan agar berkunjung ke suatu daerah tertentu. Belum adanya perkembangan dari suatu objek yang dapat menarik pengunjung/wisatawan maka belum dapat disebut sebagai daya tarik wisata sampai objek tersebut mengalami perkembangan. Pariwisata sulit dikembangkan apabila tidak terdapat daya tariknya. (Kirom et al, 2016). Wisata budaya merupakan jenis pariwisata minat khusus dengan memanfaatkan potensi sejarah yang sudah telah ada. Di satu sisi, jenis wisata ini memberi dampak ekonomi peningkatan tarif hidup masyarakat yang tinggal disekitarnya.

Lokasi juga dapat mempengaruhi minat wisatawan untuk berkunjung dikarenakan faktor ini juga salah satu untuk perbandingan wisatawan saat akan berkunjung, salah satunya jalan menuju ke lokasi yang mudah di lalui serta visibilitas, seperti terdapatnya parkir yang memadai dan terlihat jelas lokasi dari tepi jalan. Apabila kebutuhan akan keinginan terpenuhi maka wisatawan akan kembali berkunjung (Ghanapala, 2015).

Promosi merupakan media untuk mengarahkan konsumen agar mengenal barang/jasa pada tindakan pemasaran/pemasaran. (Marclina et al, 2018). Segala keindahan, keunikan berupa nilai sejarah dapat dikatakan sebagai daya tarik dan menjadi daerah tujuan utama kunjungan. Wisatawan berkunjung ke suatu daerah apabila promosi wisata yang di tawarkan dapat menarik pengunjung.

Dunia pariwisata saat ini sudah berkembang menjadi bisnis industri berkeuntungan besar. Dengan semakin kondusifnya politik, tatanan ekonomi, sosial dan budaya menunjukan pariwisata yang berkembang. Pemberi adil besar dalam perkembangan wisata dengan kemajuan teknologi informasi dan komunikasi memungkinkan produk dapat dikenal luas oleh masyarakat karena informasi yang di upload lewat situs internet dapat di baca oleh masyarakat luas. Untuk memajukan suatu daerah peran penting pemerintah dan masyarakat untuk bekerjasama memperhatikan beberapa faktor destinasi dan kemudahan. (Sutanto dan Shandy, 2016).

Keraton Kasunanan Surakarta adalah bangunan peninggalan sejarah pecahan dari keraton Jogjakarta peninggalan jaman mataram yang beralamat di Baluwarti, Kec. Ps. Kliwon, Kota Surakarta, Jawa Tengah, yang berdiri pada tahun 1744 hingga sekarang dan sebagai pengganti Istana/Keraton Kartasura akibat geger pecinan karena porak-poranda tahun 1743. Meski Kasunanan Surakarta tersebut telah resmi sejak tahun 1945 sudah menjadi bagian dari Negara Indonesia. Selain itu Sri Sultan masih menempati Keraton hingga sekarang sebagai tempat tinggalnya dan masih menjalankan tradisi-tradisi kerajaan hingga sekarang. Keraton Kasunanan ini sudah termasuk salah satu icon wisata Sebagia kompleks Keraton di dalamnya terdapat museum yang menyimpan bendabenda peninggalan sejarah, replica-replika pusaka Keraton dan gamelan. Dari segi bangunan, keraton ini merupakan contoh arsitektur istana Jawa tradisional yang terbaik. Dalam survei penelitian ini pengunjung Keraton Kasunanan Surakarta dalam 3 tahun mulai 2017 - 2019 mengalami penurunan. Yaitu dari 20.283 pengunjung pada tahun 2017 dan sampai tahun 2019 pada bulan Oktober berjumlah 9.072 pengunjung. Oleh karena itu perlu dilakukan penelitian supaya terjadi peningkatan pengunjung yang di tinjau dari daya tarik,,tempat dan promosi. Dengan uraian di atas maka penulis berpendapat layak untuk melakukan penelitian dengan judul Potensi Pariwisata Keraton Kasunanan Surakarta Di Tinjau Dari Daya Tarik, Lokasi Dan Promosi. 


\section{LANDASAN TEORI}

Potensi pariwisata adalah sebuah tujuan yang dimiliki suatu daerah wisata untuk menarik pengunjung dan dapat dikembangkan menjadi daya tarik maka dapat di sebut sebagai potensi.

Pengerak utama destinasi pariwisata adalah adanya faktor daya tarik di dalamnya. Faktor budaya merupakan salah satu daya tarik yang di wariskan dari nenek moyang untuk di kembangkan dan di kenalkan supaya menarik wisatawan agar berkunjung maka harus ada strategi untuk menjaga kebudayaan dari segi warisannya.

Lokasi adalah salah satu faktor pertimbangan wisatawan saat mau berkunjung ke Keraton Kasunanan Surakarta dikarenakan lokasi wisata yang mudah di jangkau adalah dambaan setiap calon wisatawan yang akan berkunjung ke Keraton Kasunanan Surakarta serta ada pula yang perlu di pertimbangkan dalam lokasi diantaranya akses yang mudah tempat yang nyaman dan parkir yang luas di kawasan Keraton.

Poromosi adaalah tindakan yang di perlukan oleh pengelolah guna memperkenalkan wisata pada wisatawan agar timbul kegiatan pertukaran dan pemasaran. Pengelolah sangatlah perlu melakukan kegiatan promosi karena kegitan promosi hakekatnya adalah kegiatan untuk mempengaruhi wisatawan agar menjadi kenal akan wisata yang di tawarkan oleh pengelolah dan wisatawan akan berkunjung kelokasi wisata tersebut.

\section{KERANGKA PEMIKIRAN}

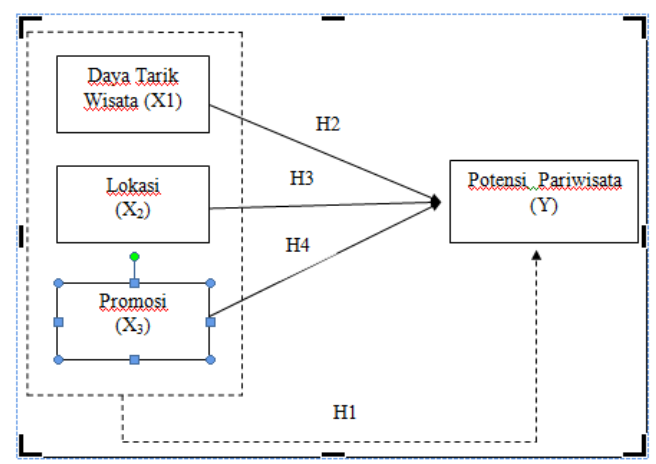

Gambar I. Kerangka Pemikkiran

\section{HIPOTESIS}

H1. Diduga terdapat pengaruh simultan dan signifikan daya tarik, lokasi, promosi terhadap potensi pariwisata Keraton Kasunanan Surakarta.

H2. Diduga terdapat pengaruh positif dan signifikan daya tarik terhadap potensi pariwisata Keraton Kasunanan Surakarta.

H3. Diduga terdapat pengaruh positif dan signifikan lokasi terhadap potensi pariwisata Keraton Kasunanan Surakarta. 
H4. Diduga terdapat pengaruh positif dan signifikan promosi terhadap potensi pariwisata Keraton Kasunanan Surakarta.

\section{METODE PENELITIAN}

Jenis penelitian kuantitatif populasinya yaitu pengunjung Keraton Kasunanan Surakarta dengan sampel 100 responden. Data diperoleh dari kuesioner dengan teknik pengambilan sampel accidental sampling. Teknik analisis data pada penelitian yaitu uji asumsi klasik, regresi linier berganda, uji $\mathrm{F}$, uji $\mathrm{t}$, dan $\mathrm{R}^{2}$.

\section{HASIL DAN PEMBAHASAN}

\section{Uji Asumsi Klasik}

1) Uji Normalitas

Tabel IV.5

Hasil Uji Normalitas

One-Sample Kolmogrov-Smirnov Test

\begin{tabular}{ccc}
\hline & Unstandarized Residual & Keterangan \\
\hline$N$ & 100 & \\
Kolmogrov-Smirnov Z & .553 & Data terdistribusi normal \\
asymp.Sig 92 tailed) & .919 & \\
\hline
\end{tabular}

Uji normalitas memiliki sebaran data yang normal. Hasil pengujian Kolmogrov - Smirnov - Test, nilai $p$ - value $(0,919>0,05)$.

2) Uji Multikolinearitas

Hasil Uji Multikolonieritas

Coefficients

\begin{tabular}{|c|c|c|c|}
\hline \multirow[t]{2}{*}{ Model } & \multicolumn{2}{|c|}{ Collinearity Statistics } & \multirow{2}{*}{ Ketrangan } \\
\hline & Tolerance & $V I F$ & \\
\hline Daya Tarik & .651 & 1.537 & Tidak terjadi multikolinearitas \\
\hline Lokasi & .992 & 1.008 & Tidak terjadi multikolinearitas \\
\hline Promosi & .655 & 1.527 & Tidak terjadi multikolinearitas \\
\hline
\end{tabular}

Uji multikolinearitas menunjukan bahwa model regresi pada penelitian ini tidak terjadi multikolinearitas. Diperoleh dari tolerance value $>0,10$ pada VIF kurang dari 10.

3) Uji Heteroskedastisitas

Hasil Uji Heteroskedastisitas

\begin{tabular}{lcc}
\hline \multicolumn{1}{c}{ Model } & Sig & \multicolumn{1}{c}{ Keterangan } \\
\hline Daya Tarik & .649 & Tidak terjadi heterokedastisitas \\
Lokasi & .360 & Tidak terjadi heterokedastisitas \\
Promosi & .072 & Tidak terjadi heterokedastisitas \\
\hline
\end{tabular}


Uji Glejser menunjukan bahwa model regresi tidak terjadi heteroskedastisitas. Dilihat dari nilai probabilitas signifikansi pada variabel independen lebih dari 0,05.

\section{Uji Regresi Linier Berganda}

\begin{tabular}{lccc} 
& Analisis Regresi Linier Berganda \\
& \multicolumn{3}{c}{ Coefficients } \\
\multicolumn{1}{c}{ Model } & $\mathrm{B}$ & Unstandardized Coefficients \\
& & & Std. Error \\
\hline 1. (Constant) & 2.894 & 1456 & \\
Daya Tarik & .026 & .057 & .047 \\
Lokasi & .043 & .062 \\
Promosi & .139 & \\
\hline
\end{tabular}

$$
\mathrm{Y}=2,894+0,026 \mathrm{X}_{1}+0,043_{2}+0,139 \mathrm{X}_{3}+\mathrm{e}
$$

\section{Keterangan:}

a. Nilai konstanta (a) sebesar 2,894 artinya variabel daya tarik, lokasi dan promosi secara positif berpengaruh terhadap potensi pariwisata sebesar 2,894.

b. Koefisien variable daya tarik $\left(b_{1}=0,026\right.$. Artinya, ketika daya tarik mengalami peningkatan satu satuan, sementara variabel lain tetap, maka variabel potensi pariwisata pembelian naik 0,026 .

c. Koefisien variabel lokasi $\left(b_{2}\right)=0,238$. Artinya, ketika lokasi naik satu satuan, sementara variabel lain tetap, maka potensi pariwisata naik 0,238.

d. Koefisien variabel promosi $\left(b_{3}\right)=0,139$. Artinya, ketika promosi naik satu satuan, sementara variabel lain tetap, maka potensi pariwisata naik 0,139 .

\section{Uji F}

Uji F (Simultan) digunakan untuk mengetahui signifikan pengaruh daya tarik, lokasi dan promosi terhadap potensi pariwisata Keraton Kasunanan Surakarta.

Hasil analisis data yang telah didapatkan, maka dapat diketahui bahwa nilai $F_{\text {hitung }}$ adalah sebesar 21,887, dikarenakan $F_{\text {hitung }}>F_{\text {tabel }}(21.887>2,70)$ dan signifikansi 0,000 $<0,05$ maka $\mathrm{H}_{0}$ ditolak. Dapat disimpulkan $\mathrm{H}_{\mathrm{a}}$ diterima, artinya daya tarik, lokasi dan promosi berpengaruh secara simultan dan signifikan terhadap potensi pariwisata Keraton Kasunanan Surakarta.

\section{Uji t}

Uji $t$ (parsial) digunakan untuk mengetahui seberapa besar variable independen memiliki daya pengaruh terhadap variabe dependen. Hasil analisis data yaitu:

1) Daya Tarik

Nilai $\mathrm{t}_{\text {tabe } 1}<\mathrm{t}_{\text {hitung }}(1,985<4,061)$ nilai signifikan $0,000<0,05$ maka $\mathrm{H}_{0}$ ditolak dan $\mathrm{H}_{1}$ diterima. Dapat disimpulkan daya tarik berpengaruh secara positif dan signifikan terhadap potensi pariwisata Keraton Kasunanan Surakarta. 
2) Lokasi

Nilai $\mathrm{t}_{\text {tabel }}<\mathrm{t}_{\text {hitung }}(1,985>0,369)$ nilai signifikan $0,713>0,05$ maka $\mathrm{H}_{0}$ diterima dan $\mathrm{H}_{1}$ ditolak. Dapat disimpulkan lokasi tidak berpengaruh secara positif dan signifikan terhadap potensi pariwisata Keraton Kasunanan Surakarta.

3) Promosi

Nilai $\mathrm{t}_{\text {tabel }}<\mathrm{t}_{\text {hitung }}(1,985<3,249)$ nilai signifikan $0,002<0,05$ maka $\mathrm{H}_{0}$ ditolak dan $\mathrm{H}_{1}$ diterima. Dapat disimpulkan lokasi berpengaruh secara positif dan signifikan terhadap potensi pariwisata Keraton Kasunanan Surakarta.

\section{Uji $\mathbf{R}^{2}$}

Nilai Adjusted $R$ Square $\left(\mathrm{R}^{2}\right)$ sebesar 0,338 atau 38,8\%. Artinya determinasi atau sumbangan variabel daya tarik, lokasi dan promosi terhadap potensi pariwisata Keraton Kasunanan Surakarta sebesar 38,8\%. Sisanya sebesar 61,2\% disumbang oleh variabel lain.

\section{PEMBAHASAN}

Dari uji $\mathrm{F}$ menunjukkan bahwa daya tarik, lokasi dan promosi secara simultan berpengaruh signifikan terhadap potensi pariwisata Keraton Kasunanan Surakarta $F_{\text {hitung }}>$ $F_{\text {tabel }}(21,887>2,70)$ dan signifikansi $0,000<5 \%$. Hasil itu membuktikan bahwa semakin tinggi daya tarik, lokasi dan promosi maka akan semakin tinggi potensi pariwisata.

Uji t menunjukan bahwa daya tarik secara parsial berpengaruh signifikan terhadap potensi pariwisata Keraton Kasunanan Surakarta diperoleh $t_{\text {tabel }}<t_{\text {hitung }}(1,985<4,061)$, nilai signifikansi $0,000<5 \%$ dan koefisien regresi meiliki nilai positif sebesar 0,386 . Artinya apabila daya tarik yang di miliki semakin menarik maka wisatawan yang akan mengunjungi Keraton Kasunanan Surakarta akan meningkat lebih banyak.

Daya tarik memiliki pengaruh yang besar terhadap potensi pariwisata Keraton Kasunanan Surakarta karena di keraton menyajikan wisata budaya yang jarang di miliki oleh tempat wisata lainnya seta banyak sejarah yang terdapat pada Keraton Kasunanan Surakarta.

Uji t menunjukan bahwa lokasi secara parsial tidak berpengaruh signifikan terhadap potensi pariwisata Keraton Kasunanan Surakarta diperoleh $t_{\text {tabel }}<t_{\text {hitung }}(1,985>$ 0,369), nilai signifikansi $0,713>5 \%$ dan koefisien regresi meiliki nilai positif sebesar 0,029. Artinya lokasi tidak berpengaruh terhadap potensi pariwisata Keraton Kasunanan Surakarta.

Dikarenakan Keraton Kasunanan Surakarta adalah icon dari kota Surakarta sendiri, jadi mau di manapun lokasi Keraton pasti wisatawan akan mengunjunginya tanpa harus melihat lokasinya dimana.

Uji t menunjukan bahwa promosi secara persial berpengaruh signifikan terhadap potensi pariwisata Keraton Kasunanan Surakarta diperoleh $t_{\text {tabel }}<t_{\text {hitung }}(1,985<3,249)$, nilai signifikansi $0,002<5 \%$ dan koefisien regresi meiliki nilai positif sebesar 0,339. Artinya Promosi memiliki pengaruh besar terhadap potensi pariwisata Keraton Kasunanan Surakarta karena promosi yang baik bakal memikat wisatawan untuk berkunjung ke Keraton Kasunanan Surakarta adapun promosi adalah sebagai alat informasi bagi wisatawan yang akan berkunjung ke Keraton Kasunanan Surakarta. Penelitian ini sejalan dengan penelitian sebelumnya. (Sutanto dan Shandy, 2016). 
Promosi berpengaruh terhadap potensi pariwisata Keraton Kasunanan Surakarta karena adanya faktor social media maka banyak wisatawan yang akan berkunjung terlebih dahulu mencari informasi tentang objek yang akan di tuju menggunakan social media.

\section{KESIMPULAN}

a. Daya tarik, lokasi dan promosi berpengaruh simultan dan signifikan terhadap potensi pariwisata Keraton Kasunanan Surakarta

b. Daya tarik $\left(\mathrm{X}_{1}\right)$ berpengaruh secara positif dan signifikan terhadap potensi pariwisata (Y) di Keraton Kasunanan Surakarta.

c. Lokasi $\left(\mathrm{X}_{2}\right)$ tidak berpengaruh secara positif dan signifikan terhadap potensi pariwisata (Y) di Keraton Kasunanan Surakarta.

d. Promosi $\left(\mathrm{X}_{3}\right)$ berpengaruh secara positif dan signifikan terhadap potensi pariwisata (Y) di Keraton Kasunanan Surakarta.

\section{Saran}

a. Pihak Keraton Kasunanan Surakarta menambah jumalah informasi tulisan pada dindingdinding bangunan Keraton.

b. Ditambahnya fasilitas umum seperti bangku untuk pengunjung yang mengalami kecapekan akibat berkeliling Keraton Kasunanan Surakarta.

c. Diadakanlah pertunjukan-pertunjukan budaya Jawa maupun Keraton.

d. Mengingat hasil pada penelitian bahwa variabel lokasi tidaklah berpengaruh terhadap potensi pariwisata.

e. Untuk di sarankan agar peneliti berikutnya dapat mengembangkan variabel di luar penelitian ini seperti budaya dan fasilitas.

\section{DAFTAR PUSTAKA}

Achmad, A. R. 2012. Daya tarik wisata pantai wediombo sebagai alternatif wisata bahari di daerah istimewa yogyakarta. Jurnal Geografi. Vol 10 No.1 (63-73)

Asti, D. D. Suryataman. Nur, E. S.2016. pemberdayaan ekonomi Masyarakat manis kidul dalam menunjang pendidikan formal di objek wisata cibulan. Jurnal edueksos. Volume V no 1. juni 2016

Dewi, H. S. dan Erick, S. H. 2016. Pentingnya promosi guna meningkatkan minat wisatawan wisata sejarah di kota lama semarang. Vol. 18 No. 01 Juni 2016

Eka, R. A. Sunarti. Edriana, P. 2017. Pengaruh daya tarik wisata dan fasilitas layanan terhadap kepuasan wisatawan di pantai balekambang kabupaten malang. Jurnal Administrasi Bisnis. Vol. 51 No. 2 oktober 2017

Eka, R. A. Sunarti. Edriana, P. 2017. Pengaruh daya tarik wisata dan fasilitas layanan terhadap kepuasan wisatawan di pantai balekambang kabupaten malang. Jurnal Administrasi Bisnis. Vol. 51 No. 2 oktober 2017 
Nicklouse, C. L. 2015. Pengaruh harga, lokasi, dan fasilitas terhadap keputusan menggunakan jasa taman wisata toar lumimuut (taman enam) sonder. Jurnal EMBA. Vol.3 No.1 Maret 2015, Hal. 1072-1083

Nila, R. Falahah. 2012. Pengembangan situs promosi pariwisata pulau flores berbasis kolaborasi. Seminar Nasional Informatika 2012 (semnasIF 2012). ISSN: 1979-2328

Novita, R. K. Sudarmiatin, I. Wayan, J. A. P. 2016. Factor-faktor penentu daya tarik wisata budaya dan pengaruhnya terhadap kepuasan wisatawan. Jurnal Pendidikan. Volume: 1 Nomor: 3 Bulan Maret Tahun 2016 Halaman: 536-546

Rizal, B. dan Nadya, O. 2019. Pengaruh lokasi, kualitas pelayanan, fasilitas dan susunan lingkungan terhadap kepuasan pengunjung kebun raya bogor. Jurnal Ekonomi Manajemen dan Akutansi. Vol. 15, No. 1, Juli 2019

Shinta, D. M. Indra, G. F. Agus, S. Slamet, B. Y. 2018. Persepsi wisatawan terhadap fasilitas wisata di pusat latihan gajah taman nasional way kambas. Jurnal Belantara [JBL] Vol. 1, No. 2, Agustus 2018 (45-53)

Sri, W. Sri, D. Weni, R. Sri, O. 2018. Presepsi wisatawan muslim terhadap sarana penunjang wisata halal dikawasan desa sembalun lawang.Jurnal Magister Manajemen. Maret 2018. eissn : 2548-3919

Stephany, Q. W. L. Silvya, M. Sjendy, L. 2015. Pengaruh advertising dan daya tarik wisata terhadap keputusan wisatawan mengunjungi obyek wisata pantai firdaus. Jurnal EMBA. Vol.3 No.3 Sept. 2015, Hal.1079-1088 